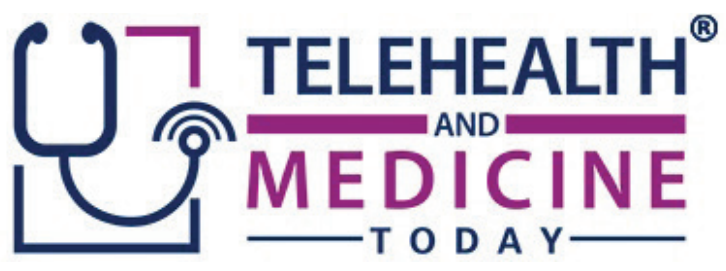

\title{
Assessment of Knowledge, Perception, and Willingness of using Telemedicine among Medical and Allied Healthcare Students Studying in Private Institutions
}

PrateekMalhotra, PGDHM Student ${ }^{1}$, Anandhi Ramachandran, PhD, PGDM(IS), PGDPHI $^{2}$, Ruby Chauhan, MPH Student ${ }^{3}$, DishaSoni, PGDHM, Student ${ }^{4}$, NupurGarg, PG, Student ${ }^{5}$

\begin{abstract}
${ }^{1}$ Health and Hospital Management, International Institute of Health Management and Research, Dwarka, New Delhi-110075, India; ${ }^{2}$ Associate Professor, International Institute of Health Management and Research, Dwarka, New Delhi-110075, India; ${ }^{3}$ Laboratory of Disease Dynamics \& Molecular Epidemiology, Amity Institute of Public Health, Amity University, Noida Sector-125, Pin- 201313, Uttar Pradesh, India; ${ }^{4}$ Diploma Hospital Management, International Institute of Health Management and Research, Dwarka, New Delhi-110075, India; ${ }^{5}$ Diploma Hospital Health Management Student, Associate at Ernest \& Young
\end{abstract}

Corresponding Author: Ruby Chauhan, Email: rubychauhan95.3@gmail.com

Keywords: Adoption of Telemedicine, Healthcare Students, India, Knowledge, Pandemic, Perception, Telemedicine

Section: Original Research

Introduction: Telemedicine is a developing technology in the Indian healthcare sector. The success of any new technology depends on factors such as knowledge, perception, and willingness of users and professionals to engage it. This study assessed the knowledge, perception, and willingness of healthcare students to use telemedicine.

Materials and methods: A cross-sectional survey was conducted among healthcare students from May 10, 2020 to June 30, 2020 in India. In this study, there were 428 individuals selected using Non-Probability Convenience Sampling and were approached through online Google Forms. The pretested study questionnaire that administered had four parts: demographic details, willingness, perception, and knowledge level. Data analysis was performed using Statistical Package for the Social Sciences (SPSS) version 25.

Results: Out of the total study population, $40 \%$ were male and $60 \%$ were female.

Forty-three percentage of the total population reported insufficient knowledge of telemedicine, and $52.1 \%$ had insufficient knowledge about its application. However, 90.9\% viewed telemedicine as a viable approach, and they were willing to use telemedicine and integrate it in their practice in future. It 
was determined that perception toward telemedicine influenced willingness for adopting in their careers.

Conclusion: Even though each participant's knowledge and awareness were limited, the majority of individuals reported positive perception and willingness toward using the telemedicine in their career. Thus, it is essential to build proper and effective communication channels and awareness among students, professionals, and users for telemedicine to succeed in India.

\section{INTRODUCTION}

As per the American Telemedicine Association (ATA), "Telemedicine is the natural evolution of healthcare in the digital world." It literally means "healing from distance," which is often used as an umbrella term that consists of healthcare delivery, in addition to education, research, health surveillance, and promotion. ${ }^{2}$ Telemedicine offers a new method of providing healthcare services across different geographical areas and is used to facilitate accessibility of healthcare services to people who do not have access to such services in their residential areas. ${ }^{3}$ The benefits provided by telemedicine include: (1) increase in healthcare accessibility; (2) reduction in overall healthcare costs to the individual; (3) real-time referrals to emergency care to avoid complications; and (4) provision of higher quality care. ${ }^{4}$ Globally, many hospitals, large healthcare systems, health insurance companies, and federal governments are turning toward the use of telemedicine to provide healthcare solutions with the support of newer technologies such as Internet of Things, fast internet bandwidth, artificial intelligence, and gadgets that allow physician to measure pulse rate, oxygen, temperature, and even chest X-rays through internet. ${ }^{5,6}$

India with its huge population has a major shortage of physicians and specialists, geographic maldistribution of primary healthcare services, overcrowding of patients in public tertiary services, and high out-of-pocket expenditure, all leading to deficit between demand and supply of healthcare services in real time. As per the World Health Organization (WHO), the doctor-population ratio should be $1: 1,000$, while the current doctor population ratio in India is only $0.62: 1,000$.

There are 279,588 beds in rural hospitals and 431,173 beds in urban hospitals, with $70 \%$ of the population of India still living in rural area, ${ }^{7}$ which stands for 1.3 beds per 1,000 population, as compare with WHO criteria of 3.5 beds per 1,000 population. ${ }^{8}$ The availability of beds in government hospital is significantly low. Moreover, lack of adequate ventilators, personal protection equipment, and spread of infection among healthcare workers complicate the situation causing imbalance between demand and supply of direct one-to-one healthcare services.

Globally, it has been brought to light that maintaining social distance (restricting physical contact to a bare minimum) among individuals, be it a physician or a patient, is the best strategy to avoid the spread of the infection. This can be realized through virtual contact between doctor and patients through telemedicine. It can also help in reducing overcrowding in hospitals, burdened with patients who are infected with COVID19. ${ }^{9}$

In India, adoption of telemedicine has been very slow. Government of India in 1999 initiated a pilot project called "Development of Telemedicine Technology." As a part of the project, a telemedicine application called "Sanjeevani" has been launched, which enables providing consultations in pathology, radiology, and cardiology. ${ }^{10}$ Indian Space Research Organization (ISRO) has created a network through geo-satellites to connect super-specialty 
hospitals with rural and remote hospitals of Jammu \& Kashmir, Andaman \& Nicobar Islands, and Lakshadweep, allowing thousands of patients to have consultations with medical experts. ${ }^{11}$

Other major government initiatives established using standardized telemedicine practice guidelines through the Department of Information Technology, National Telemedicine Task Force by the Health Ministry, in 2005, include the international projects such as PanAfrican eNetwork Project and South Asian Association for Regional Co-operation (SAARC) Telemedicine Network Project. ${ }^{1}$

Telemedicine implementations through private organizations such as Apollo Hospital in Andhra Pradesh (first of its kind in India), Rabindranath Tagore International Institute of Cardiac Sciences (RTIICS), Arvind Eye Care, Narayana Hirudalaya, Shankara Nethralaya, and government medical institutes such as All India Institute of Medical Sciences (AIMS), Post Graduate Institute (PGI) Chandigarh, and Sanjay Gandhi Postgraduate Institute of Medical Sciences (SGPGIMS) Lucknow are notable mentions in the country. ${ }^{12-16}$ The interventions are mainly focused on the domains of radiology, ophthalmology, pathology, and cardiology. Telemedicine has been found to be an excellent via media to reach out to patients and affected individuals during natural disasters and emergencies like tsunami. ${ }^{17}$

Keeping in view of the expanding growth of telemedicine worldwide and pandemic situation in the country, the Government of India on March 25, 2020 issued an amendment to Indian Medical Council 2002 a Code of Conduct to regulate telemedicine in India. ${ }^{18}$ This has provided the much-needed legal status to the practice of telemedicine in the country. Most of the telemedicine projects being implemented so far are pilot based, and few are scaled to robust projects in daily use. Along with technology, financing, organization policies, regulation framework, and infrastructure influence the success of telemedicine projects, which are primarily influenced by the adoption behavior of the providers, as well as the patients.

Earlier studies have shown that insufficient knowledge, lack of skills and training, and resistance to change are some of the important barriers for the adoption of telemedicine among healthcare professionals. ${ }^{3}$ In an article related to unintended consequences of telehealth, the authors, who are the members of the International Medical Informatics Work Group on Telehealth, identified the administrative, technical, clinical, and personal issues as barriers while using telemedicine. ${ }^{19}$ Adequate and proper knowledge about the benefits and capabilities of telemedicine can enhance the willingness to adopt and change the attitude toward telemedicine interventions. ${ }^{1,20}$ Though the barriers to adoption are associated with provider or physician experience in understanding the telemedicine space in its entirety, its benefits and uncertainties, and legal requirements by the healthcare students (clinical and nonclinical) will go a long way in helping them to adopt telemedicine and implement it successfully in their professional work.

The current pandemic situation globally has pushed the healthcare providers and patients to seek alternate forms of communication through internet, social media, and telephone, to avoid the spread of infection. This trend of use of technology is here to stay, and one can see the signs of its ubiquitous growth in the past few months. India too is caught up in this wave of change in the healthcare environment, and both government and private sectors are vigorously taking steps by promoting innovations, development of new applications and platforms, policy changes, education, and advocacy 
activities. It is important to understand the emerging healthcare professionals' (students) perception, knowledge, and awareness of telemedicine for designing, developing, and implementing capacity-building initiatives. ${ }^{21}$ Although there are studies that try to explore the perception of students toward telemedicine, ${ }^{22,23}$ there are not many studies available in the country. ${ }^{24}$ Hence, the current study is a step toward bridging this gap by exploring the knowledge, perception, and willingness about telemedicine among the healthcare students studying in private organizations (medical and allied health institutes).

\section{METHODS}

\section{Study Design and Setting}

A cross-sectional study was undertaken among healthcare students undergoing medical and allied healthcare degrees to assess the attitude, knowledge, and willingness to adopt telemedicine in their professional life. The study was conducted from May 10, 2020 to June 30, 2020 through an online survey. Healthcare students who were unwilling to participate were excluded.

\section{Sample Size and Procedure}

The sample size for this study was calculated using Cochran formula with $95 \%$ confidence interval (CI), and a proportion of telemedicine knowledge and attitude of $50 \%$ since there is no previous study done in the same population in this country, with a relative precision to be $5 \%$ at a $10 \%$ nonresponse rate. Accordingly, the sample size was calculated as 422 . This was rounded off to 430 as the final sample size.

$$
n=\frac{Z^{2} p q}{d^{2}}
$$

where $n$ is the sample size, $Z$ is the statistic for level of confidence $(Z=1.96), p$ is the expected proportion of knowledge about telemedicine in the target population ( $p=50 \%)$, and $d$ is the precision $(d=0.05)$.

$n=1.96^{2}(0.5)(0.5)$

------------------ $=384$

$(0.05)(0.05)$

Anticipated nonresponse rate of $10 \%=38$, and a total sample size $(384+38=422)$ rounded off to 430 .

A Non-Probability Convenience Sampling method was adopted to recruit participants for this study. Healthcare students (medical and nonmedical) in the age limit of 18-35 years were the target population.

Since the country is in the lockdown phase, instead of direct survey, an online-based survey was designed. The tool used for data collection was a structured questionnaire administered online through Google Survey. A link to Google form was circulated through various social networks, which also included a brief introduction to the study, its purpose, and consent form. Only students who agreed to fill the consent form were allowed to undergo the survey. No personal identification was collected.

\section{Study Tool and Analysis}

Data were collected by using structured selfadministered questionnaire designed for the study. The study questionnaire was designed and modified on the basis of previously published research articles ${ }^{15,25}$ and evaluated by two experts in the field. The questionnaire consists of four parts as follows.

Part 1 consisted of sociodemographic information of the participants (four items): gender, age, education (medical and nonmedical), and location (rural and urban). 
Part 2 consisted of questions related to knowledge of the healthcare students about telemedicine (five items), rated based on a 5-point Likert scale (" 1 = very low" to " 5 = very high"). The respondents can score a minimum of 5 and maximum of 25 . The questions are "To what extent are you familiar with telemedicine (process and benefits)?," "To what extent are you familiar with telemedicine applications and platforms within country?," "To what extent are you familiar with use of telemedicine outside country?," "To what extent are you familiar with recent released guidelines of telemedicine in the country?," and "To what extent do you participate in conferences and webinars related to telemedicine?"

Part 3 investigated the perception of the students toward telemedicine (five items). These include "Telemedicine is a viable approach for providing comprehensive healthcare to the patient," "Telemedicine enables adoption of technology in healthcare," "Telemedicine saves time and reduces effort (work-load)," "Telemedicine helps in reducing cost of service," and "There are existing telemedicine applications in the country that can be easily adopted."

Part 4 assessed the willingness of the students to adopt telemedicine in their professional career (six items). The questions include "Will you use telemedicine applications for consultation?," "Will you refer and advise telemedicine interventions to your peers and friends?," "Will you ever include or practice telemedicine in your practice to provide patient care?," "Are you willing to pay for telemedicine applications," "Are you willing/open to consult colleagues through video conferencing regarding patient?," and "Are you willing to integrate telemedicine with existing system to providing care?"

Both parts 3 and 4 are assessed through dichotomous variables "Agree" $($ score $=1)$ and
"Disagree" $($ score $=0)$. Each respondent can score a minimum of 0 and a maximum of 5 in perception and a minimum of 0 and a maximum of 6 in willingness to adopt.

In this study, the average score of $5(50 \%)$ from the 10 questions was used as a cut-off point to determine the perception toward telemedicine. The mean perception score less than $5(50 \%)$ was labeled as low perception toward telemedicine, and more than average score of $5(50 \%)$ was labeled as good perception toward telemedicine.

Data analysis was done using the Statistical Package of Social Science (SPSS) software version 25. Data were first extracted into Excel spreadsheets and then fed into IBM SPSS. Descriptive statistics such as frequency and percentage were used to express various parameters and for the comparison of categorical data. Chi-square test was used, and $p$ value $<0.05$ was considered statistically significant. Pearson's correlation was used to determine the association between knowledge, perception, and willingness, and, with a $p$ value of $<0.001$ was considered statistically significant.

\section{Ethical Considerations}

The current paper is based on the summer training assignment by student authors. The participants were provided details of the study objectives and purpose. A consent form was the first part of the self-administered online tool. In order to maintain anonymity, only those who provided consent electronically (without revealing the personal details) were allowed to access the rest of the tool. No personal identification details such as contact number, address, name, and email details of the participants were collected. The subjects did not belong to vulnerable group (more than 18 years of age, nonpregnant/lactating, non-tribal, and non-vulnerable section of the society). Based on 
these criteria, the study was exempted from IRB (investigational review board) review.

\section{RESULTS}

A total of 430 subjects were approached through email and social media. Only two refused to sign the consent form and were excluded. The final completed responses were received from 428 respondents. Out of these, $40 \%$ were men and $60 \%$ were women. The mean age of the study participants was $24.7 \pm 3.3$ years. Nearly $51.4 \%$ respondents were undergoing undergraduate medical degrees (MBBS, BDS, BAMS, BHMS, BUMS, and nursing). The rest (48.6\%) were from nonclinical courses (MPH, MHA, MBA in health and hospital management, and other allied medical science courses). Almost all the students $(90.4 \%)$ hailed from urban areas, while $9.6 \%$ of respondents were from rural areas. The sociodemographic details of the respondents are represented in Table 1.

One major finding of the study is that $43 \%$ of study participants had insufficient knowledge

Table 1. Socio-demographic characteristics of the study participants $(N=428)$

\begin{tabular}{|l|r|r|}
\hline Characteristics & \multicolumn{2}{|c|}{ \% } \\
\hline $\begin{array}{l}\text { Age in years (mean } \pm \\
\text { standard deviation) }\end{array}$ & \multicolumn{2}{|c|}{} \\
\hline 18-25 years & 295 & 68.9 \\
\hline 26-35 years & 133 & 31.1 \\
\hline Gender & & \\
\hline Female & 256 & 59.8 \\
\hline Male & 172 & 40.2 \\
\hline Course & & \\
\hline Clinical & 220 & 51.4 \\
\hline Nonclinical & 208 & 48.6 \\
\hline Location & & \\
\hline Rural & 41 & 9.6 \\
\hline Urban & 387 & 90.4 \\
\hline
\end{tabular}

about telemedicine, while $38 \%$ had average and $18.9 \%$ had high knowledge about telemedicine. Here, knowledge regarding telemedicine refers to basic awareness regarding telemedicine process and its benefits to healthcare. When enquired about awareness to telemedicine, only $15.7 \%$ had fairly good or high knowledge, and nearly $52.1 \%$ had insufficient knowledge. Very few attended webinars or conferences related to telemedicine (13.1\%) and were aware of the new telemedicine guidelines (14.7\%). Awareness and familiarity among the students regarding the adoption of telemedicine in countries other than India was also low (60.3\%) (Table 2).

Knowledge related to telemedicine and its application were analyzed with respect to the level of education. Based on the nature of the degree course (clinical vs. nonclinical), there was significant difference among knowledge about telemedicine and its applications within the country (Table 3).

Students undergoing clinical degrees seem to be overall more aware of telemedicine than students undergoing nonclinical degrees. Within each group of students, the number having high knowledge related to telemedicine was very low (16.8\% - clinical and 21.2\% - nonclinical). Greater percentage of clinical students reported attending webinars/conferences related to telemedicine compared with nonclinical students. There was no significant difference among clinical and nonclinical students regarding awareness to telemedicine guidelines and telemedicine adoption in countries other than India.

On analyzing the influence of gender on knowledge regarding telemedicine, awareness related to national and international telemedicine applications, and frequency of attending telemedicine webinars were slightly more among female students than male students. 
Table 2. Overall knowledge of the healthcare students about telemedicine and telemedicine applications

\begin{tabular}{|c|c|c|c|}
\hline \multirow{2}{*}{$\begin{array}{l}\text { Questions } \\
\text { Total students }=428\end{array}$} & \multicolumn{3}{|c|}{ No. of students, $N(\%)$} \\
\hline & Low $\left(N_{\mathbf{L}}\right)$ & Average $\left(N_{\text {Avg }}\right)$ & $\operatorname{High}\left(N_{\mathbf{H}}\right)$ \\
\hline Knowledge about telemedicine & $184(43)$ & $163(38.1)$ & $81(18.9)$ \\
\hline $\begin{array}{l}\text { Knowledge related to telemedicine applications within } \\
\text { country }\end{array}$ & $223(52.1)$ & $138(32.2)$ & $67(15.7)$ \\
\hline Frequency of attending webinar and conferences & $279(65.2)$ & $93(21.7)$ & $56(13.1)$ \\
\hline $\begin{array}{l}\text { Awareness and knowledge of current guidelines of } \\
\text { telemedicine }\end{array}$ & $272(63.6)$ & $93(21.7)$ & $63(14.7)$ \\
\hline Familiarity with the use of telemedicine in other countries & $258(60.3)$ & $111(25.9)$ & $59(13.8)$ \\
\hline
\end{tabular}

Table 3. Influence of education on knowledge about telemedicine

\begin{tabular}{|c|c|c|c|c|c|}
\hline Questions & Levels & $\begin{array}{l}\text { Clinical courses } \\
(N[\%])\end{array}$ & $\begin{array}{c}\text { Nonclinical } \\
\text { courses }(\boldsymbol{N}[\%])\end{array}$ & $\chi^{2}$ & $p$ \\
\hline \multirow{3}{*}{$\begin{array}{l}\text { Knowledge about } \\
\text { telemedicine }\end{array}$} & Low $(N=184)$ & $113(26.4)$ & $71(16.6)$ & \multirow{3}{*}{13.111} & \multirow{3}{*}{$0.001 *$} \\
\hline & Average $(N=163)$ & $70(16.4)$ & $93(21.7)$ & & \\
\hline & $\operatorname{High}(N=81)$ & $37(8.6)$ & $44(10.3)$ & & \\
\hline \multirow{3}{*}{$\begin{array}{l}\text { Knowledge related to } \\
\text { telemedicine applications } \\
\text { within country }\end{array}$} & Low $(N=223)$ & $133(31.1)$ & $90(21)$ & \multirow{3}{*}{12.681} & \multirow{3}{*}{$0.002 *$} \\
\hline & Average $(N=139)$ & $58(13.6)$ & $80(18.7)$ & & \\
\hline & $\operatorname{High}(N=67)$ & $29(6.8)$ & $38(8.9)$ & & \\
\hline \multirow{3}{*}{$\begin{array}{l}\text { Frequency of attending } \\
\text { webinar and conferences }\end{array}$} & Low $(N=279)$ & $154(36)$ & $125(29.2)$ & \multirow{3}{*}{6.636} & \multirow{3}{*}{$0.036^{*}$} \\
\hline & Average $(N=93)$ & $37(8.6)$ & $56(13.1)$ & & \\
\hline & $\operatorname{High}(N=56)$ & $29(6.8)$ & $27(6.3)$ & & \\
\hline \multirow{3}{*}{$\begin{array}{l}\text { Awareness and knowledge } \\
\text { of current guidelines of } \\
\text { telemedicine }\end{array}$} & Low $(N=272)$ & $135(31.5)$ & $137(32)$ & \multirow{3}{*}{3.263} & \multirow{3}{*}{0.196} \\
\hline & Average $(N=93)$ & $46(10.7)$ & $47(11)$ & & \\
\hline & $\operatorname{High}(N=63)$ & $39(9.1)$ & $24(5.6)$ & & \\
\hline \multirow{3}{*}{$\begin{array}{l}\text { Familiarity with use of } \\
\text { telemedicine in other } \\
\text { countries }\end{array}$} & Low $(N=258)$ & $136(31.8)$ & $122(28.5)$ & \multirow{3}{*}{0.929} & \multirow{3}{*}{0.629} \\
\hline & Average $(N=111)$ & $57(13.3)$ & $54(12.6)$ & & \\
\hline & $\operatorname{High}(N=59)$ & $27(6.3)$ & $32(7.5)$ & & \\
\hline
\end{tabular}

*Significant at $p<0.05$.

Based on Chi-square test, age had no influence on the level of knowledge related to telemedicine among healthcare students regarding telemedicine.

Students, by gender and age, (Table 4, 5) queried regarding their perception related to telemedicine as a viable source for providing healthcare services in the country. Overall, $93 \%$ of respondents reported that they think technology has a viable role to play in healthcare sector $(p<$ 0.05 ), and $90.1 \%$ of the study participants perceived telemedicine as a practical approach for providing care to patients $(p<0.05)$. There were 
Table 4. Influence of gender on knowledge about telemedicine

\begin{tabular}{|c|c|c|c|c|c|}
\hline Questions & Levels & Female $(N[\%])$ & Male (N [\%]) & $\chi^{2}$ & $p$ \\
\hline \multirow{3}{*}{$\begin{array}{l}\text { Knowledge about } \\
\text { telemedicine }\end{array}$} & Low $(N=184)$ & $104(24.3)$ & $80(18.7)$ & \multirow{3}{*}{1.471} & \multirow{3}{*}{0.479} \\
\hline & Average $(N=163)$ & $102(23.8)$ & $61(14.3)$ & & \\
\hline & $\operatorname{High}(N=81)$ & $50(11.7)$ & $31(7.2)$ & & \\
\hline \multirow{3}{*}{$\begin{array}{l}\text { Knowledge related to } \\
\text { telemedicine applications } \\
\text { within country }\end{array}$} & Low $(N=223)$ & $125(29.2)$ & $98(22.9)$ & \multirow{3}{*}{4.875} & \multirow{3}{*}{$0.087 * *$} \\
\hline & Average $(N=138)$ & $93(21.7)$ & $45(10.5)$ & & \\
\hline & $\operatorname{High}(N=67)$ & $38(8.9)$ & $29(6.8)$ & & \\
\hline \multirow{3}{*}{$\begin{array}{l}\text { Frequency of attending } \\
\text { webinar and conferences }\end{array}$} & Low $(N=279)$ & $162(37.9)$ & $117(27.3)$ & \multirow{3}{*}{7.412} & \multirow{3}{*}{$0.025^{*}$} \\
\hline & Average $(N=93)$ & $66(15.4)$ & $27(6.3)$ & & \\
\hline & $\operatorname{High}(N=56)$ & $28(6.5)$ & $28(6.5)$ & & \\
\hline \multirow{3}{*}{$\begin{array}{l}\text { Awareness and knowledge } \\
\text { of current guidelines of } \\
\text { telemedicine }\end{array}$} & Low $(N=272)$ & $161(37.6)$ & $111(25.9)$ & \multirow{3}{*}{1.375} & \multirow{3}{*}{0.503} \\
\hline & Average $(N=93)$ & $60(14)$ & $33(7.7)$ & & \\
\hline & $\operatorname{High}(N=63)$ & $35(8.2)$ & $28(6.5)$ & & \\
\hline \multirow{3}{*}{$\begin{array}{l}\text { Familiarity with the use } \\
\text { of telemedicine in other } \\
\text { countries }\end{array}$} & Low $(N=258)$ & $149(34.8)$ & $109(25.5)$ & \multirow{3}{*}{5.213} & \multirow{3}{*}{$0.074 * *$} \\
\hline & Average $(N=111)$ & $76(17.8)$ & $35(8.2)$ & & \\
\hline & $\operatorname{High}(N=59)$ & $31(7.2)$ & $28(6.5)$ & & \\
\hline
\end{tabular}

*Significant at $p<0.05$. * Significant at $p<0.01$.

Table 5. Influence of age on knowledge about telemedicine

\begin{tabular}{|c|c|c|c|c|c|}
\hline Questions & Levels & $\begin{array}{c}\text { 18-25 years } \\
(n[\%])\end{array}$ & $\begin{array}{c}\text { 26-35 years } \\
(n[\%])\end{array}$ & $\chi^{2}$ & $p$ \\
\hline \multirow{3}{*}{$\begin{array}{l}\text { Knowledge about } \\
\text { telemedicine }\end{array}$} & Low $(N=184)$ & $129(30.1)$ & $55(12.9)$ & \multirow{3}{*}{0.280} & \multirow{3}{*}{0.869} \\
\hline & Average $(N=163)$ & $110(25.7)$ & $53(12.4)$ & & \\
\hline & $\operatorname{High}(N=81)$ & $56(13.1)$ & $25(5.8)$ & & \\
\hline \multirow{3}{*}{$\begin{array}{l}\text { Knowledge related to } \\
\text { telemedicine applications } \\
\text { within country }\end{array}$} & Low $(N=223)$ & $161(37.6)$ & $62(14.5)$ & \multirow{3}{*}{3.391} & \multirow{3}{*}{0.184} \\
\hline & Average $(N=138)$ & $87(20.3)$ & $51(11.9)$ & & \\
\hline & $\operatorname{High}(N=67)$ & $47(11)$ & $20(4.7)$ & & \\
\hline \multirow{3}{*}{$\begin{array}{l}\text { Frequency of attending } \\
\text { webinar and conferences }\end{array}$} & Low $(N=279)$ & $197(46)$ & $82(19.2)$ & \multirow{3}{*}{3.381} & \multirow{3}{*}{0.184} \\
\hline & Average $(N=93)$ & $57(13.3)$ & $36(8.4)$ & & \\
\hline & $\operatorname{High}(N=56)$ & $41(9.6)$ & $15(3.5)$ & & \\
\hline \multirow{3}{*}{$\begin{array}{l}\text { Awareness and knowledge } \\
\text { of current guidelines of } \\
\text { telemedicine }\end{array}$} & Low $(N=272)$ & $191(44.6)$ & $81(18.9)$ & \multirow{3}{*}{0.709} & \multirow{3}{*}{0.702} \\
\hline & Average $(N=93)$ & $61(14.3)$ & $32(7.5)$ & & \\
\hline & $\operatorname{High}(N=63)$ & $43(10)$ & $20(4.7)$ & & \\
\hline \multirow{3}{*}{$\begin{array}{l}\text { Familiarity with use of } \\
\text { telemedicine in other } \\
\text { countries }\end{array}$} & Low $(N=258)$ & $174(40.7)$ & $84(19.6)$ & \multirow{3}{*}{0.667} & \multirow{3}{*}{0.716} \\
\hline & Average $(N=111)$ & $79(18.5)$ & $32(7.5)$ & & \\
\hline & $\operatorname{High}(N=59)$ & $42(9.8)$ & $17(4)$ & & \\
\hline
\end{tabular}


$25.2 \%$ respondents who disagreed with the statement that telemedicine is already available in India $(p<0.05), 91.4 \%$ of the students agreed that telemedicine saves time and money, and $87.4 \%$ agreed that it saves work too.

Influence of type of the course being undertaken, gender, and age on the perception was analyzed. There was little significant difference among students undergoing medical education from nonmedical students.

Similarly, there was no significant difference in the overall perception related to telemedicine due to gender and age differences. However, students undergoing clinical courses showed no difference (45.8\%) in their perception regarding telemedicine as a viable approach to provide healthcare service in the country versus nonclinical students (45.8\%). Surprisingly, clinical students increasingly disagreed more than nonclinical students regarding the availability of telemedicine (Table 6).

Lastly, respondents were surveyed regarding their willingness to adopt telemedicine in their practice (Table 7). Among the 430 students who participated in the survey, $96.4 \%$ students showed willingness to adopt telemedicine in their professional career. More than $80 \%$ of the students had a positive perception toward the adoption of telemedicine, and $85 \%$ respondents agreed that telemedicine system can be integrated within the existing system

Table 6. Influence of type of course against perception of telemedicine

\begin{tabular}{|c|c|c|c|c|c|c|}
\hline Questions & Levels & $\begin{array}{c}\text { Clinical } \\
\text { courses }(n[\%])\end{array}$ & $\begin{array}{c}\text { Nonclinical } \\
\text { courses }(n[\%])\end{array}$ & $\begin{array}{l}\text { Total } \\
(\%)\end{array}$ & $x^{2}$ & $p$ \\
\hline \multirow{2}{*}{$\begin{array}{l}\text { Telemedicine - a viable approach } \\
\text { for providing care to patient }\end{array}$} & Disagree & $27(6.3)$ & $12(2.8)$ & 9.1 & \multirow[t]{2}{*}{5.460} & \multirow[t]{2}{*}{$0.019 *$} \\
\hline & Agree & $193(45.1)$ & $196(45.8)$ & 90.9 & & \\
\hline \multirow{2}{*}{$\begin{array}{l}\text { Telemedicine already available } \\
\text { in India }\end{array}$} & Disagree & $74(17.3)$ & $43(10)$ & 27.3 & \multirow[t]{2}{*}{9.045} & \multirow[t]{2}{*}{$0.003^{*}$} \\
\hline & Agree & $146(34.1)$ & $165(38.6)$ & 72.7 & & \\
\hline
\end{tabular}

*Significant at $p<0.05$.

Table 7. Willingness of the students to adopt telemedicine

\begin{tabular}{|l|l|r|}
\hline \multirow{2}{*}{$\begin{array}{l}\text { Wuestions } \\
\text { applingness to pay for telemedicine }\end{array}$} & Disagree & $67(15.7)$ \\
\cline { 2 - 3 } $\begin{array}{l}\text { Open to consult colleagues through } \\
\text { video conferencing }\end{array}$ & Agree & $361(84.3)$ \\
\hline \multirow{2}{*}{$\begin{array}{l}\text { Open to use of telemedicine } \\
\text { for consultation }\end{array}$} & Disagree & $76(17.8)$ \\
\cline { 2 - 3 } & Agree & $352(82.2)$ \\
\hline \multirow{2}{*}{$\begin{array}{l}\text { Willingness to refer telemedicine } \\
\text { applications to friends and peers }\end{array}$} & Disagree & $58(13.6)$ \\
\cline { 2 - 3 } $\begin{array}{l}\text { Readiness to practise telemedicine } \\
\text { interventions for providing care }\end{array}$ & Agree & $370(86.4)$ \\
\hline \multirow{2}{*}{$\begin{array}{l}\text { Willingness to integrate telemedicine } \\
\text { with existing system to provide care }\end{array}$} & Disagree & $54(12.6)$ \\
\cline { 2 - 3 } & Agree & $374(7.4)$ \\
\cline { 2 - 3 } & Disagree & $69(16.1)$ \\
\cline { 2 - 3 } & Agree & $359(83.9)$ \\
\hline
\end{tabular}


Table 8. Association between knowledge, perception of telemedicine, and willingness to adopt among healthcare students

\begin{tabular}{|l|c|c|} 
& \multicolumn{2}{c|}{$\begin{array}{r}\text { Pearson correlation } \\
\text { coefficient } \\
\end{array}$} \\
& $\begin{array}{c}\text { Perception } \\
\text { score }\end{array}$ & $\begin{array}{c}\text { Willingness } \\
\text { score }\end{array}$ \\
\hline Knowledge score & $0.161^{* *}$ & $0.212^{* *}$ \\
\hline Perception score & & $0.509^{* *}$ \\
\hline
\end{tabular}

**Correlation is statistically significant at the 0.001 level.

$(p<0.001)$. There were $84.3 \%$ of the participants willing to pay for telemedicine in India and $83.9 \%$ of the respondents were willing to include telemedicine in their practice.

There was no significant difference between clinical and nonclinical students regarding willingness to adopt telemedicine. Age and gender too had no influence over willingness of the healthcare students regarding telemedicine.

Another major finding of the study was the association between knowledge, perception, and willingness as evaluated through correlation analysis. Knowledge was more positively related to willingness, $r(428)=0.212, p<0.001$, than to perception $r(428)=0.161, p<0.001$ (Table 8). Perception toward telemedicine did influence willingness to adopt telemedicine in one's professional career.

\section{DISCUSSION}

In the current situation, where COVID-19 pandemic has restricted the visits of patients to hospitals unless emergency, telemedicine has the potential to provide successful doctor-patient interaction, aid in health promotion, and increase access to healthcare services in the remote areas. ${ }^{26}$ It may reduce isolation, prevent uncomfortable delays in availing healthcare services, and help in increasing patient numbers. Successful adoption of telemedicine in healthcare especially depends majorly on the healthcare professional's knowledge and attitude toward the adoption of the technology by the patients. There are number of earlier studies that indicate knowledge and perception of healthcare professionals, which affect telemedicine adoption. ${ }^{3,27}$ One approach to promote telemedicine adoption among healthcare professionals is to understand their awareness related to telemedicine and expose them to telemedicine practices earlier during their education since student's education has a great impact on their knowledge and opinion regarding their future work..$^{20,28}$ The purpose of the current study is to assess the knowledge, perception, and willingness of healthcare students toward telemedicine.

The study revealed that only $18.9 \%$ of the healthcare students heard about telemedicine, only $15.7 \%$ of the students were aware of telemedicine-related applications, and only $14.7 \%$ were aware of the new guidelines related to telemedicine in the country. Our study findings related to knowledge are consistent with the findings of other studies, where only $14.7 \%$ could describe telemedicine and its use correctly. ${ }^{24}$ A study conducted in northern Iran among 532 clinicians has reported that the majority of their study participants $(96.1 \%)$ had insufficient knowledge regarding telemedicine. ${ }^{3}$ Another study conducted in Puducherry, India, among 120 professionals in a tertiary hospital has also shown the similar results, where it was found that 59\% had insufficient knowledge about telemedicine. ${ }^{27}$ Such lack of awareness and knowledge related to telemedicine may be due to less exposure to telemedicine-related applications in their course and also due to the adoption of telemedicine being in nascent stage in the country. This might change as the current pandemic situation in the country has exposed the importance of telemedicine that has given a 
push to greater number of telemedicine adoptions, webinars, and online trainings being conducted and telemedicine guidelines being released. This is further reflected in our study finding that more students (75\%) perceived that telemedicine implementations already in vogue in the country.

The healthcare students surveyed had high positive perception toward telemedicine. More than $90 \%$ of the students perceived that telemedicine solutions are viable in the country. More than $80 \%$ felt the adoption of telemedicine in healthcare to provide services can reduce time and cost. In an earlier study in West Bengal, it was found that $60 \%$ of the respondents felt telemedicine was cost-effective. ${ }^{24}$ Similar such positive perceptions toward telemedicine have been reported in earlier studies. ${ }^{29,30}$ As telemedicine reduces patient's revisits to the hospital due to the unavailability of doctors, long-distance travel to hospitals and healthcare centers, and revisits for follow-up, it is perceived that there will be a significant reduction in time and cost especially to the patients. This may be due to the fact that as students being trained to become doctors and administrators, they could foresee an adoption of telemedicine by them or their organization and the benefit that might arise.

Even though the participants had insufficient knowledge regarding telemedicine, surprisingly, majority of them $(84.3 \%)$ were willing to adopt and pay for this technology. These study findings are consistent with the study conducted among 150 postgraduate students of tertiary hospitals in West Bengal, where they stated that $76 \%$ of the study population were willing to pay for telemedicine. ${ }^{24}$ As per the study conducted in Riyadh among 391 physicians, it was found that $95 \%$ of them reported their willingness to start this technology and use it to consult in a larger institution. ${ }^{25}$ Further, $83.9 \%$ of respondents were open to use telemedicine in their practice. This is higher than a similar such study in Nigeria, where $54.2 \%$ were in support of using telemedicine for routine care. ${ }^{31}$ Most of the students $(85 \%)$ felt that telemedicine could be integrated well into the existing healthcare system and used for providing services at remote area. Similar such perception has been reported in studies conducted among clinicians in Malaysia, where $80 \%$ of respondents wanted to connect remote districts through telemedicine. ${ }^{21}$ Similar such perception highlighted that in spite of technical issues that might arise, telemedicine is beneficial and cost-effective. ${ }^{32}$ Though our study revealed that knowledge might influence perception toward the telemedicine and willingness to adopt in career, it is the perception that influences the healthcare student's readiness to use telemedicine. This indicates if more and more healthcare students need to be encouraged toward adopting telemedicine, their perception toward telemedicine's adoption and its benefit should be positive. This can happen only if their awareness toward telemedicine implementations is increased.

Though telemedicine has been implemented in India by the law from March 25, 2020, based on our study, one could perceive lots of challenges such as lack of understanding, awareness, communication, and trust on technology. The main reason for this could be attributed to the fact that the exposure to telemedicine of healthcare students in India is limited as compared with other countries. ${ }^{24}$ The present study reveals important information about the knowledge, perception, and willingness on the part of healthcare students, who are expected to be the future of the healthcare sector and shoulder the responsibility of widespread adoption of telemedicine. Even though telemedicine has become a part of medical act, it is suggested that, before implementation, it is essential to increase user's knowledge of the 
technology and illustrate its capabilities and benefits. Enhanced knowledge and clear perceptions of technology will help them to accept it. This can be done by including telemedicine as a part of the student curriculum and capacitating them through training programs. In a study conducted among 143 doctors at 14 different hospitals in India, irrespective of the age, all the respondents agreed that telemedicine was important and hospital training programs are required for proper utilization of telemedicine. ${ }^{33} \mathrm{~A}$ training intervention that was carried out among staff nurses for telemedicine in Bengaluru proved that this is an effective method to increase the awareness toward telemedicine and increase adoption. ${ }^{34}$ This is the right time, as the attitude and perception of physicians and also patients toward telemedicine and adoption of technology are changing due to the present scenario of COVID-19. Recent most articles regarding the use of telemedicine in ophthalmology stand as a testimony to this. ${ }^{35}$

The main limitation of the study is that due to COVID-19-induced lockdown, it was based on convenience sampling through online survey. Hence, the findings could not be attributed to a larger population. It would be more generalizable and more useful if a larger sample of healthcare students in more regions could be covered. Nevertheless, as such studies related to knowledge, perception, and willingness among healthcare students are very less, this study is expected to contribute to close the gap.

\section{CONCLUSION}

Even though participant's knowledge and awareness were limited, the majority of individuals reported positive perception and willingness toward using the telemedicine in their career. Thus, it is essential to build proper and effective communication channels and awareness among students, professionals, and users for telemedicine to succeed in India.
Funding Statement: The study was not supported through external funding.

Conflicts of Interest: The authors declare that there is no conflicts of interest.

Contributors: Authors PM, DS, RC, NG, and AR were involved collaboratively in the study. PM, DS, and RC conceptualized, developed the tool, and carried out the study. NG contributed to the initial draft, reviewing and editing. AR and $\mathrm{RC}$ contributed to data analysis. Also, AR completed the interpretation, review, and editing of the final draft.

\section{REFERENCES}

1. Chellaiyan VG, Nirupama AY, Taneja N. Telemedicine in India: Where do we stand? J Fam Med Prim Care. 2019;8(6):1872-6.

2. Wilson LS, Maeder AJ. Recent directions in telemedicine: Review of trends in research and practice. Healthc Inform Res. 2015;21(4):213-22.

3. Ayatollahi H, Sarabi FZ, Langarizadeh M. Clinicians' knowledge and perception of telemedicine technology. Perspect Health Inf Manag. 2015;12(Fall):1c.

4. Donelan K, Barreto EA, Sossong S, Michael C, Estrada JJ, Cohen AB, et al. Patient and clinician experiences with telehealth for patient follow-up care. Am J Managed Care. 2019;25(1):40-4.

5. Zanaboni P, Wootton R. Adoption of telemedicine: From pilot stage to routine delivery. BMC Med Informat Decis Making. 2012;12(1):1.

6. Huang KJ, Cen G, Qiu ZJ, Jiang T, Cao $\mathrm{J}, \mathrm{Fu} \mathrm{CY}$. Application of international videoconferences for continuing medical education programs related to laparoscopic surgery. Telemed $J e$ Health. 2014;20(2):157-160. https://doi. org/10.1089/tmj.2013.0070

7. NHP-2018.pdf [Internet]. [cited 2020 Oct 7]. Available from: https://cdn.downtoearth.org. in/pdf/NHP-2018.pdf 
8. Bridge trust deficit between private healthcare providers, govt.: FICCI [Internet]. [cited 2020 Oct 7]. Available from: https:// www.outlookindia.com/

9. Telemedicine during COVID-19: Benefits, limitations, burdens, adaptation $\mid$ Healthcare IT News [Internet]. [cited 2020 Oct 7]. Available from: https://www.healthcareitnews. com/news/telemedicine-during-covid-19benefits-limitations-burdens-adaptation

10. Sood SP, Bhatia JS. Development of telemedicine technology in India: "Sanjeevani"-An integrated telemedicine application. J Postgrad Med. 2005;51(4): 308-11.

11. Indian Space Research Organisation (2005) ISRO Annual Report 2004-2005: Space applications [Internet]. [cited 2015 Dec 27]. Available from: http//www.isro.org/rep2005/ SpaceApplications.htm

12. Ganapathy K, Ravindra A. Telemedicine in India: The Apollo story. Telemed J e Health. 2009;15(6):576-85.

13. Mahadevan S, Muralidhar K, Shetty D. Tele-education service using telemedicine network in healthcare industry. Telemed $\mathrm{Je}$ Health. 2012;18(9):699-702.

14. John S, Sengupta S, Reddy SJ, Prabhu P, Kirubanandan K, Badrinath SS. The SankaraNethralaya mobile teleophthalmology model for comprehensive eye care delivery in rural India. Telemed $J e$ Health. 2012;18(5):382-7.

15. Kapoor L, Mishra SK, Singh K. Telemedicine: Experience at SGPGIMS, Lucknow. $J$ Postgrad Med. 2005;51(4):312-15.

16. Mehta KG, Chavda P. Telemedicine: A boon and the promise to rural India. J Rev Prog. 2013;1:1-3.

17. Gogia SB. Providing Tele mental health services after disasters - Based on the Post Tsunami experience. In: Ada S, editor. Cases in managing e services [Internet]. [cited 2008 Jan]. Pennsylvania, PA: IGI Global, 2009; p. 238-52. Available from: http://www.igi-global.com/bookstore/ chapter.aspx?titleid=6425 https://doi. org/10.4018/978-1-60566-064-6.ch016
18. Telemedicine.pdf [Internet]. [cited 2020 Oct 7]. Available from: https://www. mohfw.gov.in/pdf/Telemedicine.pdf

19. Gogia SB, Maeder A, Mars M, Hartvigsen G, Basu A, Abbott P. Unintended consequences of tele health and their possible solutions. Yearb Med Inform. 2016;1:41-6.

20. MacNeill V, Sanders C, Fitzpatrick R, Hendy J, Barlow J, Knapp M, et al. Experiences of front-line health professionals in the delivery of telehealth: A qualitative study. $\mathrm{Br} \mathrm{J}$ Gen Pract. 2014;64(624):e401-7. https://doi. org/10.3399/bjgp14X680485

21. Izham M, Ibrahim M, Phing CW, Palaian S. Evaluation of knowledge and perception of Malaysian health professionals about telemedicine. J Clin Diagn Res. 2010;3:2052-2057.

22. Shahpori R, Hebert M, Kushniruk A, Zuege D. Telemedicine in the intensive care unit environment-A survey of the attitudes and perspectives of critical care clinicians. J Crit Care. 2011;26(3):328.e9-15.

23. Badea M, Floroian L, Floroian D, Moga M, Rogozea L. Telemedicine and telediagnosis - General perception of young students from Romania. Med Sci. 2014;7(56):139-46.

24. Dey DTK, Bhattacharya DS. Knowledge and perception of telemedicine among post graduate students of a tertiary hospital of West Bengal. J Dent Med Sci. 2016;(6):8-11.

25. Albarrak AI, Mohammed R, Almarshoud N, Almujalli L, Aljaeed R, Altuwaijiri S, et al. Assessment of physician's knowledge, perception and willingness of telemedicine in Riyadh region, Saudi Arabia. J Infect Public Health. 2019;3:1-18.

26. Glinkowski WM, Saracen A. Telenursing First experiences with mobile phones for wound healing monitoring (role of nurses). Global Telemed e Health. 2010;3:597-600.

27. Zayapragassarazan Z, Kumar S. Awareness, knowledge, attitude and skills of telemedicine among health professional faculty working in teaching hospitals. $J$ Clin Diagn Res. 2016;10(3):JC01-4. https://doi. org/10.7860/JCDR/2016/19080.7431 
28. Levy S, Strachan N. Child and adolescent mental health service providers' perceptions of using telehealth. Ment Health Pract. 2013;17(1):28-32. https://doi.org/10.7748/ mhp2013.09.17.1.28.e810

29. Biruk K, Abetu E. Knowledge and attitude of health professionals toward telemedicine in resource-limited settings: A cross-sectional study in North West Ethiopia. $J$ Healthc Eng. 2018;2018:2389268. https://doi. org/10.1155/2018/2389268

30. Baig M, Khaliq T, Safdar C. Perceptions of post-graduate medical students, regarding effectiveness of telemedicine: As an instructional tool. Pakistan Armed Forces Med J. 2014;64:614-23.

31. Abodunrin O, Akande T. Knowledge and perception of e-health and telemedicine among health professionals in Lautech teaching hospital, Osogbo, Nigeria. Int $J$ Health Res. 2009;2(1):51-8.

32. Acharya RV, Rai JJ. Evaluation of patient and doctor perception toward the use of telemedicine in Apollo Tele Health Services, India. J Fam Med Prim Care. 2016;5(4):798.
33. Meher SK, Tyagi RS, Chaudhry T. Awareness and attitudes to telemedicine among doctors and patients in India. J Telemed Telecare. 2009;15(3):139-41. https://doi.org/10.1258/jtt.2009.003011

34. Khan I, Dhanalakshami MK, Naveena $\mathrm{JH}$. Effectiveness of SIM on knowledge regarding telemedicine among the staff nurses. Int Nurs Crit Care. 2016;1(1):2016.

35. Sharma M, Jain N, Ranganathan S, Sharma N, Honavar SG, Sharma N, et al. Teleophthalmology: Need of the hour. Indian J Ophthalmol. 2020;68:1328-38.

Copyright Ownership This is an open access article distributed in accordance with the Creative Commons Attribution NonCommercial (CC BY-NC 4.0) license, which permits others to distribute, adapt, enhance this work non-commercially, and license their derivative works on different terms, provided the original work is properly cited and the use is non-commercial. See: http:// creativecommons.org/licenses/by-nc/4.0. 